\title{
Tsunami Vulnerability and Risk Assessment of Banda Aceh City through ArcGIS Software
}

\author{
Mery Silviana \\ Department of Civil Engineering, Al Muslim University,Matang Glumpang Dua, Indonesia \\ silvianamery@gmail.com
}

\begin{abstract}
ARTICLE INFO
ABSTRACT

Article history:

Accepted

This research produced a tsunami risk map of village's community in Banda Aceh from a low level to a high level risk. Disaster risk analysis techniques involve a set of multi-criteria and Geographic Information Systems (GIS). GIS is used as a method to evaluate the multi-criteria which are made into spatial data and combining them into a risk map. Disaster risk assessment involves two factors: the tsunami hazard assessment and vulnerability of community. Tsunami hazard's level is measured based on the map of the tsunami's

Keywords:

Disaster risk

Risk map

Hazard assessment

GIS

Vulnerability intensity by the number of damaged buildings that is produced by JICA study team on the Indian Ocean Tsunami in 2004, while the vulnerability of community is evaluated from hazard exposure and coping capacity of society in social, economic and physical dimension. Result of study shows two villages that have an extremely high degree of risk, 36 villages have a high degree of risk, 11 villages have a medium risk, 12 villages have a low risk and 29 villages have no risk at all.
\end{abstract}

Copyright (C) 2020 Politeknik Aceh Selatan. All rights reserved.

\section{Introduction}

Banda Aceh is located in Aceh Province. Aceh Province is situated in the western part of Sumatra Island. This province is geographically lies between the two tectonic plates, the Eurasian plate and the Indo-Australian plate. The movement between the Eurasian plate and the IndoAustralian plate produces a series of island arc (Forearch Islands) or non-volcanic prismatic accretion zone and Bukit Barisan Mountains with volcanic tracks in the middle, and the active fault "The Great Sumatran Fault" which divides the island of Sumatra from the Gulf Semangko to Banda Aceh and extended into the sea of Andaman. This fault makes Sumatra Island as the areas prone to earthquakes. Therefore, the province of Aceh also is on the high seismic activity zone [1]. Going back dozen years ago, massive earthquake happened in Aceh Province. The earthquake triggered Tsunami that causes about 70,000 people out of 250,000 total victims came from the city of Banda Aceh. It is one of extremely devastated cities due to low altitude and proximity of city core to the coast. Tsunamis are low-frequency natural events but have a great destructive power when striking coasts around the world, involving loss of life and extensive damage to infrastructure and coastal communities worldwide [2]. Tsunami low-frequency but it is always threatens people who live in coastal areas [3].

Learn from experience, a comprehensive knowledge about the risk and vulnerability of tsunami to communities is very essential.

The goal of the research is to assess disaster risk level of tsunami on local community level or village's community in Banda Aceh through spatial multi-criteria analysis. The final result of the 
research will be a map that described a tsunami risk level as an input in considering the spatial and urban planning and risk management of the city in the term of sustainable development.

\section{Literature Review}

\section{A. Tsunami Hazard}

Disaster is an impact of a hazard. Hazard is the likely frequency of occurrence of a dangerous event in a fixed future time, Exposure measures people, property, systems, or other elements present in hazard zones that are thereby subject to potential losses, Vulnerability is the proportion of lives or goods likely to be lost, and accounts for the features of a system or asset that make it susceptible to the damaging effects of a hazard. This definition identifies vulnerability as a characteristic of the element of interest (community, system or asset) which does not depend on its exposure [3-4]

Tsunamis are a series of large sea waves caused by the displacement of a large volume of water caused mostly by submarine earthquakes, but can also include landslides, volcanic eruptions, and meteor impacts. Tsunamis are a high-impact, low-probability event that, although rare, are extremely destructive, resulting in high casualty rates and billions of dollars of economic loss (e.g., Indian Ocean, 2004; Samoa, 2009; Chile, 2010 and Japan, 2011)[6]. Tsunami is categorized as a long wave in water surfaces waves which much longer wavelength than water depth. It is generated offshore at depths of several thousand meters by a sudden sea bottom deformation [7].

Tsunamis in Indonesia are mostly caused by earthquakes. Indonesia lies between two oceans (the Pacific and Indian Oceans) and two continents (Australia and Asia). Situated in the meeting point of three highly active tectonic plates (Eurasian, India-Australia and Pacific plates),this archipelagic country is prone to earthquakes and tsunamis [8].

\section{B. Vulnerability}

Vulnerability as a key element of the risk assessment also considers the positive capacities of people to cope with the impact of hazards. Vulnerability consists of two elements degree of exposure to hazard, on one hand, and coping or adaptive capacity on the other [9]. Exposure is the presence of people, livelihoods, species or ecosystems, environmental functions, services, and resources, infrastructure, or economic, social, or cultural assets in places and settings that could be adversely affected. Adaptive or coping capacity is the ability of systems, institutions, humans and other organisms to adjust to potential damage, to take advantage of opportunities, or to respond to consequences [10]

The characteristics of vulnerability determined by physical, social, economic and environmental factors or processes which increase the susceptibility of an individual, a community, assets or systems to the impacts of hazards [5]

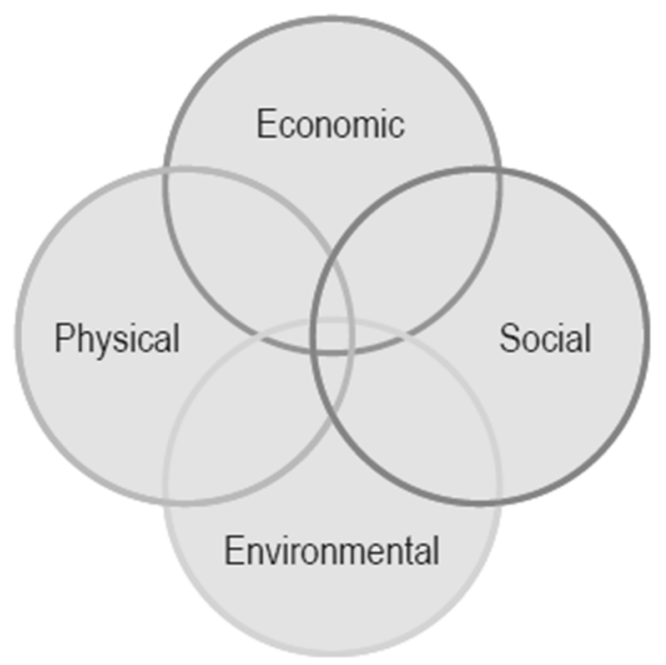

Fig.2. Interaction of Vulnerability Factors 


\section{GIS and Risk Assessment}

Risk is the probability of harmful consequences, or expected losses (deaths, injuries, property, livelihoods, economic activity disrupted or environment damaged) resulting from interactions between natural or human-induced hazards and vulnerable conditions[3-8]. Risk $=$ Hazard Potential (H) x Vulnerability (V) [12].

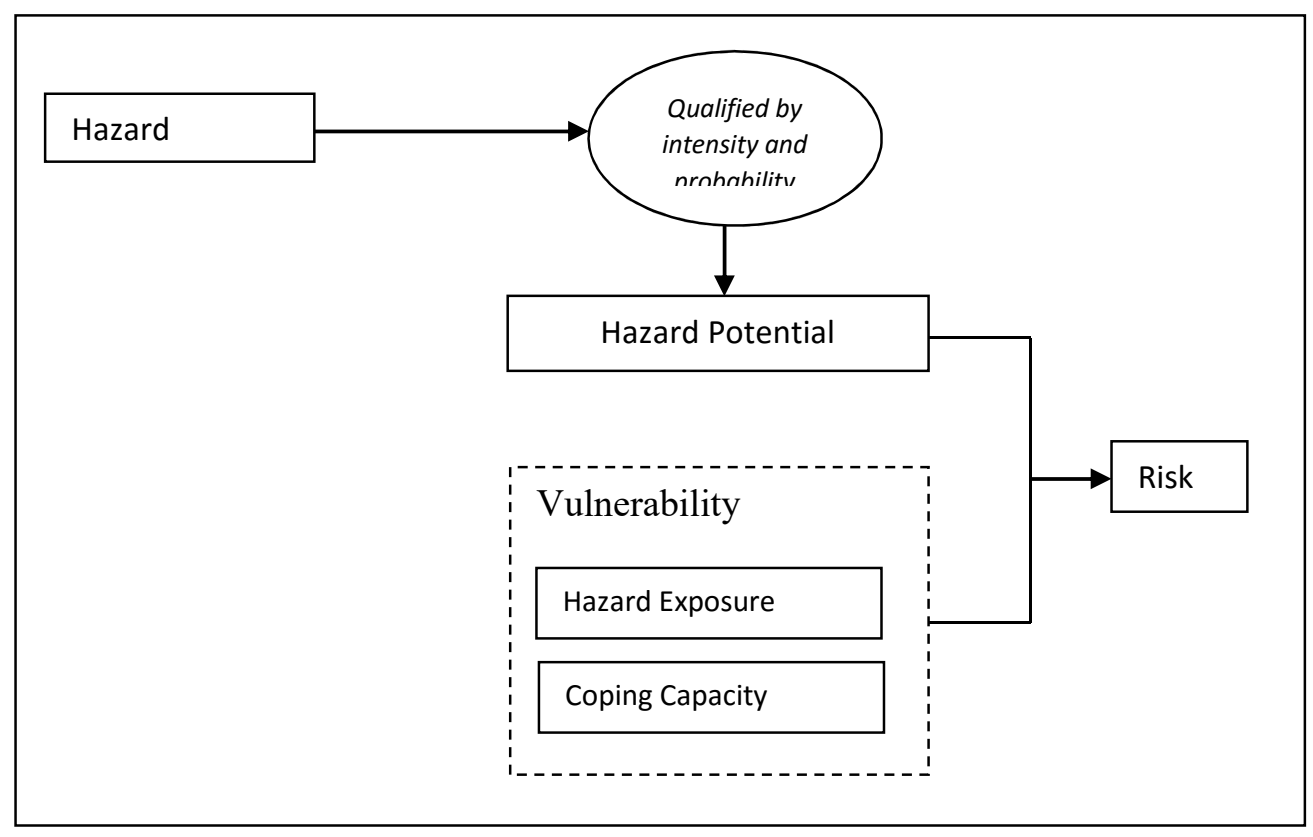

Fig.2. Component of Risk

GIS has the capability of storing, retrieving, processing and analyzing multi-source spatial or temporal datasets. GIS plays as a tool for spatial analysis to become easily accessible and develop. GIS can solve problems in many sectors including in disaster risk and spatial planning [13].

\section{Method}

In the research, the assessment of tsunami risk by using GIS approach (ArcGIS). A set multicriteria analysis is set up and transferred into spatial multicriteria, hence, a thematic map as end result could be produced.

Multicriteria analysis relates to two components of risk: hazard potential and vulnerability. Hazard potential in this study defined by map of the tsunami's intensity by the number of damaged buildings that is released by JICA study team on the Indian Ocean Tsunami in 2004 [14]. While vulnerability that consist hazard exposure and coping capacity are defined ini three dimension. For hazard exposure determined by social dimension: population; economic dimension: number of small industry, big/medium industry, agriculture area and fish pond area; physical dimension: built up area

Coping capacity also characterized by three dimensions, social capacity: number of medical workers, sex ratio, number of disability people and village development classification; economic capacity: level of poverty; physical capacity: number of permanent houses. The used data is statistical data 2015 [15].

Furthermore, all of criteria are classified to four classes: low, medium, high and very high class therefore it can be developed into spatial criteria (map) using ArcGIS. This set spatial multi-criterion is weighted and overlaid using ArcGIS tool "weighted overlay" thus, a tsunami risk map of village's community can be produced. The weighting of set multi-criteria of hazard exposure and coping capacity are shown in Table 1 and Table 2. 


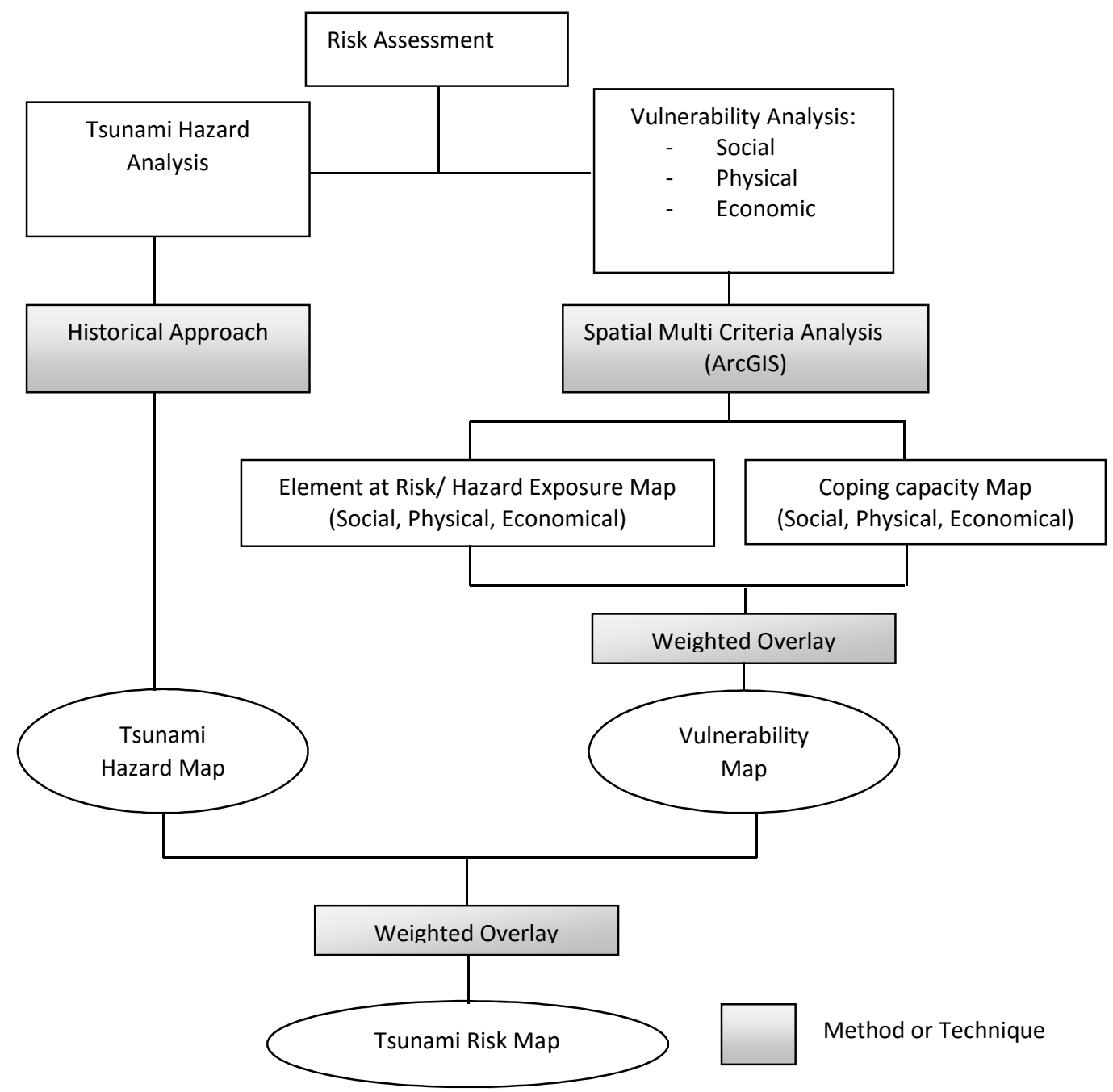

Fig.2. Data Analysis and Evaluation Method of Risk Assessment

Table 1. Weighting of Hazard Exposure Criteria

\begin{tabular}{lcllc}
\hline \multicolumn{1}{c}{ Dimension } & Weight & \multicolumn{1}{c}{ Indicator/Criteria } & Measurement & Weight \\
\hline Social Exposure & 40 & Population & Population Density & 40 \\
\hline Economic Exposure & 25 & Big/medium Industry & Number of big/medium industry & 5 \\
\cline { 3 - 5 } & & Small Industry & Number of small industry & 10 \\
\cline { 3 - 5 } & & Agricultural Area & Area of Crops, Paddy land Ratio & 5 \\
\cline { 2 - 4 } & & Fish Pond Area & Area of Fish Pond Ratio & 5 \\
\hline Physical Exposure & 35 & Built up Area & Built up Area Ratio & 35 \\
\hline
\end{tabular}

Table 2. Weighting of Coping Capacity of Communities

\begin{tabular}{ccllc}
\hline Dimension & Weight & \multicolumn{1}{c}{ Indicator/Criteria } & Measurement & Weight \\
\hline Social capacity & 55 & Medical workers & $\begin{array}{l}\text { Ratio of doctors, nurses, } \\
\text { midwife }\end{array}$ & 5 \\
\cline { 3 - 4 } & Disability people & Disability ratio & 10 \\
\hline
\end{tabular}




\begin{tabular}{|c|c|c|c|c|}
\hline & & Sex ratio $(\mathrm{m} / \mathrm{f})$ & $\begin{array}{l}\text { Sex ratio (number of male/ } \\
\text { female) }\end{array}$ & 30 \\
\hline & & $\begin{array}{l}\text { Village's Ability and } \\
\text { Development }\end{array}$ & $\begin{array}{l}\text { Level of ability and } \\
\text { development }\end{array}$ & 10 \\
\hline Economic capacity & 10 & Poverty & Level of poverty & 10 \\
\hline Physical capacity & 35 & Permanent Housing & Ratio of permanent housing & 35 \\
\hline
\end{tabular}

\section{Results and Discussion}

\section{A. Hazard Exposure, Coping Capacity and Vulnerability}

According to Table 1, weighting of hazard exposure criteria, social exposure has the biggest score because it is related to loss of human life then the second score given to physical exposure then the last is economic exposure. Each indicator of criteria is represented as a map then the maps were weighted and overlaid to produce a hazard exposure map that shown in Fig. 3. From the map it can be seen that the level of potential damage or exposure in the almost coastal area is low. Many communities of Banda Aceh are in the second level which indicates the middle exposure level..

Another factors constructed the vulnerability is coping capacity. The concerned dimension also relates to social, economic and physical dimension. Among the indicators and measurements, disability people ratio has difference concept in constructing coping capacity. The low value of disability people ratio means the high value of social capacity. Hence in the input of calculation coping capacity, the inverse value assigned to it. The weight given to respective dimension and measurement to calculating coping capacity level can be seen in the Table 2 . The given weight of coping capacity attributes also considered the importance relative of attributes. Among measured dimension, social dimension has the highest weight due to it is mostly seen as capacity in reducing the victims of life loss. Moreover, in social capacity, it also measured people's capacity in withstanding to tsunami hazard by using village's ability and development parameter which also implied the level of people's education. The resulted of weighted map is shown in the Fig. 4. The map shows the coping capacity level of communities in Banda Aceh. According to the figure, there is no first level of coping capacity which indicates "low coping capacity". Almost villages of Banda Aceh are in third level (High) of coping capacity. There are several villages that have middle level of coping capacity. Those villages are located in the Baiturrahman, Lueng Bata and Ulee Kareng Subdistrict. From the resulted map, it is also found that there are several villages have very high coping capacity to withstand with hazard. The village communities are located in Jaya Baru, Kuta Raja, Kuta Alam and Syiah Kuala Sub District.

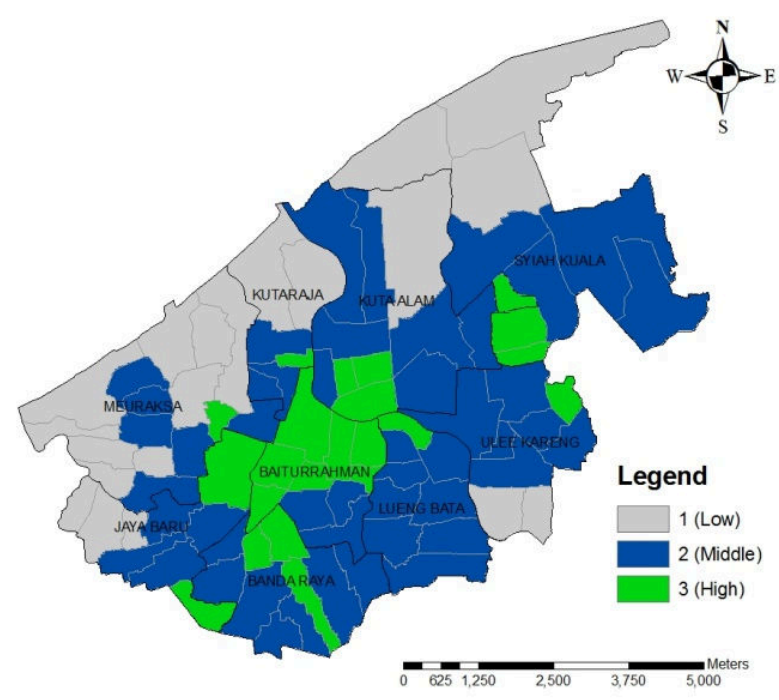

Fig.3 Map of Hazard Exposure

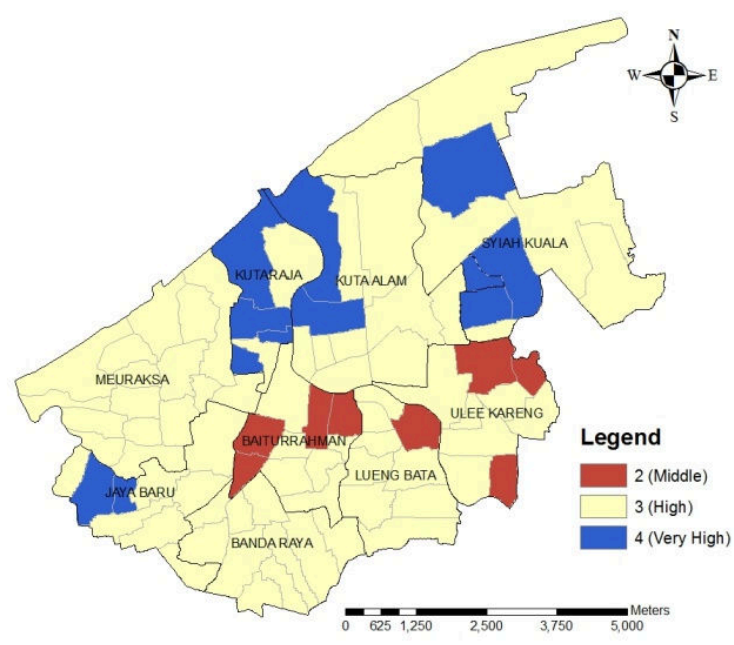

Fig. 4 Map of Coping Capacity 
The deriving maps that indicate level of exposure or damage potential and coping capacity of the community are used to assess the vulnerability. In the term of vulnerability, coping capacity is seen as reducing the possibility losses of communities. In this tool it is seen that the low capacity of communities will increase the vulnerability, on the other hand, high coping capacity will reduce the vulnerability since vulnerability is a combined factors of damage potential and coping capacity.

Combining elements of hazard exposure or damage potential with coping capacity of community resulted vulnerability map that can be seen in the Fig.5

The map is resulted from the element exposure and coping capacity of communities. By weighting them in equal by $50 \%$, then the map was produced. According to the map, at first glance the most villages have level of vulnerability in second and third class. This means the vulnerability of communities located from the middle until oigh Level. However, there is presence of village that has low vulnerability, four villages in west, east and north part of Banda Aceh are identified has low vulnerability. Those village are Lamjame, Lampoh Daya, Gampong Pande and Tibang are identified have low vulnerability level. From the figure, it also found that there is no very high vulnerability level applied in Banda Aceh.

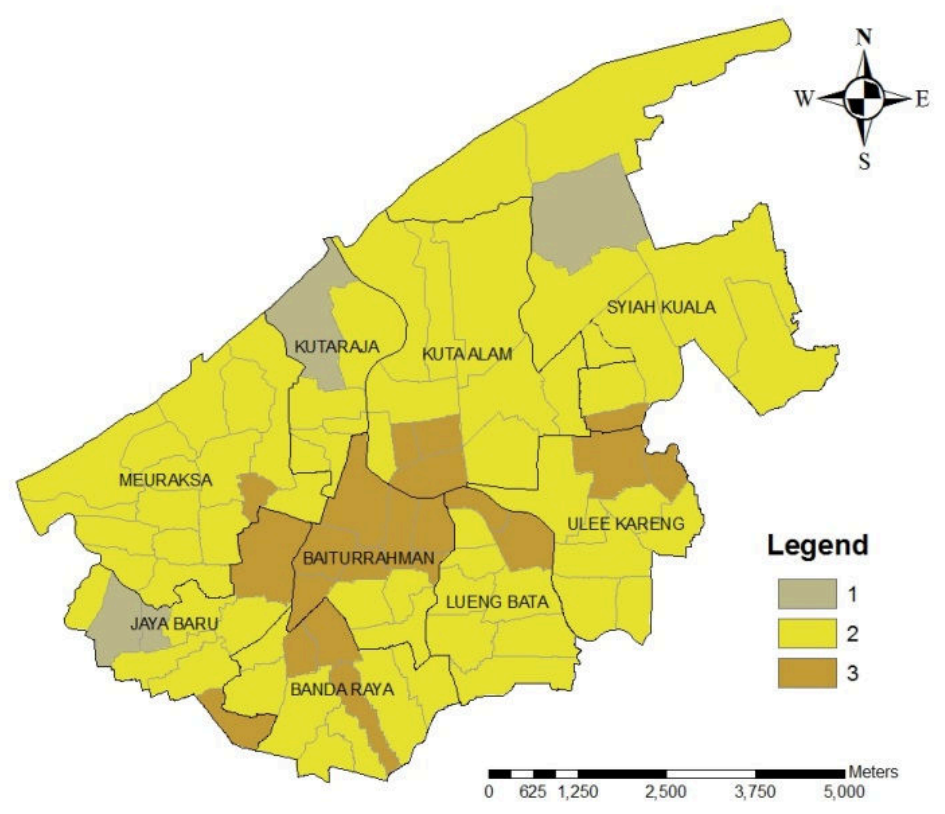

Fig.5. Map of Vulnerability

\section{B. Risk Assessment}

Once the vulnerability level of communities has been found, the risk assessment can be conducted. The method of risk assessment is more or less the same with vulnerability evaluation. The needed component factors are vulnerability and tsunami hazard assessment. According to the chapter before, tsunami hazard is already assessed which eventually produced a map of tsunami hazard assessment. This map consists of four classes that identified from 1 to 4 means from low to very high intensity. As mentioned before this map is classified based on the damage level of buildings and houses that is a research doing by JICA study team. The map is shown in the Fig.6. For vulnerability, based on the vulnerability map, Banda Aceh city has level of vulnerable from 1 to 3 , which means the villages have low, middle and high vulnerability.

The equal influence weighted by $50 \%$ of those elements considering that these elements have same importance to determine the risk of tsunami. The result of weighted overlaid those two: vulnerability and tsunami hazard assessment results a Tsunami risk level map that can be seen in the Fig.7. 


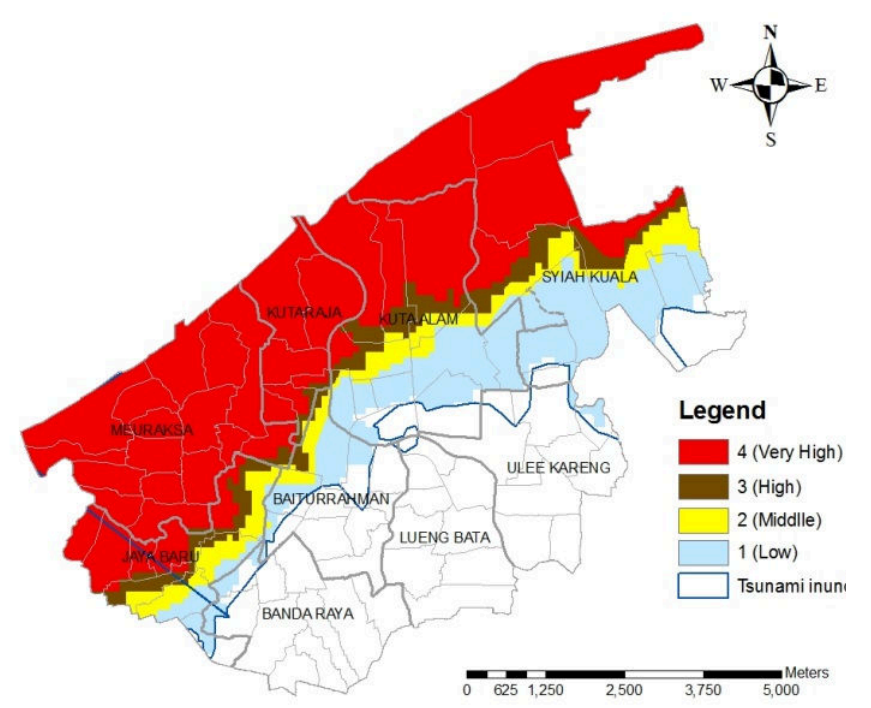

Fig.6. Tsunami Hazard Map

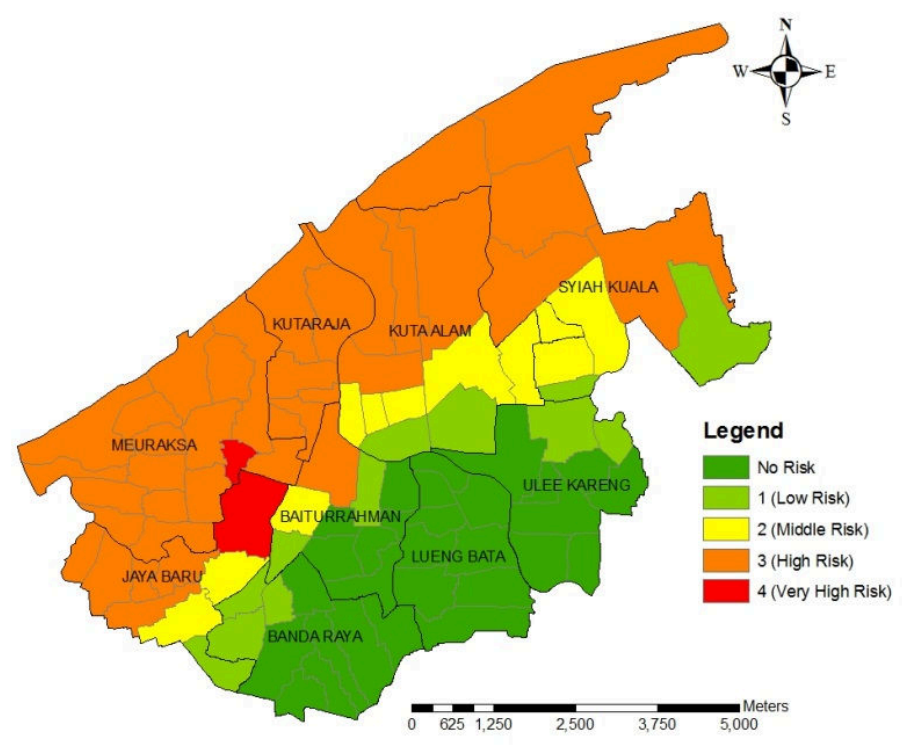

Fig.7. Tsunami Risk Map

From the Fig.7, at first glance it can be seen that almost communities of the city have risk of tsunami. More than half of total numbers of Banda Aceh's Villages have a risk. Communities located in the south or far from the shore may safer since the hazard is likely not reaching the places.

On the other hand, based on the map, it can be seen that villages which located in coastal area are mostly have high risk of tsunami. Very high risk of tsunami is applied into two villages which approximately located from 2 to $4 \mathrm{~km}$ from the shore. This happened since these villages have high vulnerability level and also include in area that potential hit by high tsunami intensity. Moreover, the middle regions of city mostly have middle risk level, this relates to tsunami intensity of the area is reduced due to general characteristics of tsunami wave. It is also found, there are communities that have low risk since they basically only impacted by the seepage of tsunami wave which is not that destructed

From 90 villages, there are 29 villages have not impacted by tsunami, 12 villages are identified to have low risk, 11 villages potential having middle risk, most impacted villages are in the high risk and only two villages threatened having very high risk of tsunami. Those villages are Punge Ujong and Punge Blang Cut where located in Meuraksa Sub District

\section{Conclusion}

According to analysis of communities in related factors of vulnerability and risk assessment through spatial criteria analysis, it is found that the hazard exposure of Banda Aceh communities including social, economical and physical dimension is in the range low to high level. Based on the result, there is no indication the communities have very high level of hazard exposure. Furthermore, in the term of coping capacity, Banda Aceh communities are in the middle to very high level which means the communities are well cope in the case of tsunami disaster which encompasses three dimensions: social, economical and physical capacity. This statement supported also by the result of interview which basically evaluated the people awareness and preparedness in the case of tsunami disaster. Through the interview, it is found that the interviewed people who come from several work backgrounds have a good knowledge of tsunami and indeed they know what to do first when tsunami strike.

As the idea of measuring vulnerability is by combining elements damage potential or hazard exposure and coping capacity, it is found that vulnerability of Banda Aceh communities are varied from low to high vulnerability. However, the result shows there is no very high vulnerable level applied the communities since there is no very high level of damage potential accompanied by no low coping capacity level of village's communities. Although, research findings found that there is 
no low vulnerability but it does not mean there is no very high tsunami risk because in evaluation tsunami risk, tsunami hazard assessment also involved. According to the result of tsunami risk that is an overlaid of tsunami hazard map and vulnerability map, the class 4 which indicates very high risk level of tsunami is appeared. This occurred because the tsunami hazard assessment factor.

Once the risk map has obtained, the risk analysis has to be done because the result did not show exactly which risk level a community stand for. The result of risk analysis shows that there are 29 communities have not threatened by tsunami disaster. These communities located quite far from the shore. Furthermore, there are 12 villages identified to have low risk of tsunami, 11 villages in the middle risk, 36 villages have high risk of tsunami and 2 villages have very high risk of tsunami. From the results, it can be concluded most villages in Banda Aceh are have risk of tsunami and it varied from low to very high. In addition, the assessment of tsunami risk is highly dependent also on the hazard assessment even a community has low vulnerability but if the threatened hazard is very high, the community might be have a high risk of hazard.

These research findings are quite helpful for Banda Aceh land city planning. The finding of tsunami risk level of communities might be one of guiders for government in risk mitigation management. The measures of the risk reduction could be in varied ways through physical action, regulation and policy. Land management system is one of important measures considering risk mitigation. The result shows that communities from 0-3 km near the shore have high risk of tsunami. In land management system, this fact could be an input to consider dense population restriction in those high risk areas or prohibited zone for inhabited in coastal area in order to reduce loss and risk. Not only that, the result also could be considered in determining evacuation area for shelter during or after disaster in temporarily or permanently. As withering hazard, it is likely whole village is damaged by the tsunami and takes weeks or months of village to be ready to re inhabited. Obviously, it requires area to be safe places for the village's inhabitants. Therefore knowing risk level of communities, it expected that the government can determine the area for evacuation. In regards to evacuation, the result also could be as a knowledge in decided the escape buildings of village during tsunami strike. Knowing number of inhabitant and risk level of village, the government can consider where and how many escape buildings could be provided to safe the people. Also another physical measure like location of tsunami early warning alarm system can be determine from considering the tsunami risk level of villages.

Physical measures such as built wall-breaking waves and mangrove coverage along the coast also are another ways in reducing tsunami risk. Through those physical measure it is expected that the power and intensity of tsunami can be reduce so that when tsunami overwhelming the land, the wave's power is not that strong like before. These measures are related to the tsunami hazard assessment as one of main elements to determine risk level of tsunami.

\section{References}

[1] M. Affan, M. Syukri, L. Wahyuna, and H. Sofyan, "Spatial Statistic Analysis of Earthquakes in Aceh Province Year 1921-2014: Cluster Seismicity," Aceh Int. J. Sci. Technol., 2016, doi: 10.13170/aijst.5.2.4878.

[2] I. Aguirre-Ayerbe et al., "From tsunami risk assessment to disaster risk reduction - The case of Oman," Nat. Hazards Earth Syst. Sci., 2018, doi: 10.5194/nhess-18-2241-2018.

[3] P. Subardjo and R. Ario, "Uji Kerawanan Terhadap Tsunami Dengan Sistem Informasi Geografis (SIG) Di Pesisir Kecamatan Kretek, Kabupaten Bantul, Yogyakarta,” J. Kelaut. Trop., 2016, doi: 10.14710/jkt.v18i2.519.

[4] I. Alberico et al., "The tsunami vulnerability assessment of urban environments through freely available datasets: The case study of Napoli city (Southern Italy)," J. Mar. Sci. Eng., 2015, doi: 10.3390/jmse3030981.

[5] UNISDR, “2009 UNISDR Terminology on Disaster Risk Reduction,” Int. Strat. Disaster Reduct., 2009, doi: 978-600-6937-11-3. 
[6] N. Attary, V. U. Unnikrishnan, J. W. van de Lindt, D. T. Cox, and A. R. Barbosa, "PerformanceBased Tsunami Engineering methodology for risk assessment of structures," Eng. Struct., 2017, doi: 10.1016/j.engstruct.2017.03.071.

[7] S. Koshimura, "Tsunami,” in Encyclopedia of Ocean Sciences, 2019.

[8] M. A. Marfai et al., "Tsunami hazard mapping and loss estimation using geographic information system in Drini Beach, Gunungkidul Coastal Area, Yogyakarta, Indonesia," in E3S Web of Conferences, 2019, doi: 10.1051/e3sconf/20197603010.

[9] C. J. van Westen and S. Greiving, "Multi-hazard risk assessment and decision making," in Environmental Hazards Methodologies for Risk Assessment and Management, 2017.

[10] M. Tiepolo, M. Bacci, S. Braccio, and S. Bechis, "Multi-hazard risk assessment at community level integrating local and scientific knowledge in the Hodh Chargui, Mauritania," Sustain., 2019, doi: 10.3390/su11185063.

[11] V. November and Y. Leanza, Risk, disaster and crisis reduction: Mobilizing, collecting and sharing information. 2015.

[12] S. H. Santius, "Pemodelan Tingkat Risiko Bencana Tsunami Pada Permukiman di Kota Bengkulu Menggunakan Sisterm Informasi Geografis,” J. Permukim., vol. 10, no. 2, pp. 92-105, 2015.

[13] W. H. Nur, Y. Kumoro, and Y. Susilowati, "GIS and Geodatabase Disaster Risk for Spatial Planning," in IOP Conference Series: Earth and Environmental Science, 2018, doi: 10.1088/17551315/118/1/012046.

[14] J. I. C. A. (JICA) and N. D. P. A. (BAPPENAS), "The Study on The Urgent Rehabilitation and Reconstruction Support Program For Aceh Province and Affected Areas in North Sumatera (Urgent Rehabilitation and Reconstruction Plan For Banda Aceh City) In the Republic of Indonesia,” 2005.

[15] B. P. S. (BPS) K. B. Aceh, Banda Aceh Dalam Angka. Banda Aceh: Badan Pusat Statistik (BPS), 2015. 